\title{
COVID-19 Pandemic: Stock Markets Reaction to the Mortality Rates and Lockdown Policies
}

\author{
Yixiu Zhao ${ }^{1}$, Min Hua ${ }^{2, *}$ \\ ${ }^{1}$ School of Economics and Management, Harbin Engineering University, Harbin, China \\ ${ }^{2}$ Faculty of Professional Finance \& Accountancy, Shanghai Business School, Shanghai, China \\ Email address: \\ zhaoyixiu@hrbeu.edu.cn (Yixiu Zhao),21210016@sbs.edu.cn (Min Hua) \\ ${ }^{*}$ Corresponding author
}

\section{To cite this article:}

Yixiu Zhao, Min Hua. COVID-19 Pandemic: Stock Markets Reaction to the Mortality Rates and Lockdown Policies. International Journal of Economics, Finance and Management Sciences. Vol. 9, No. 5, 2021, pp. 178-182. doi: 10.11648/j.ijefm.20210905.12

Received: September 8, 2021; Accepted: September 26, 2021; Published: September 29, 2021

\begin{abstract}
The coronavirus (COVID-19) pandemic is disrupting the world as we knew it, with a heavy toll on economic activities and the structure of politics. Governments, media websites, and research institutions update information about the changes in the COVID-19 epidemic every day. The most intuitive information may be the changes in the number of confirmed cases and deaths, which shape investors' sentiments and confidence in the financial markets. The goal of this study is to investigate the impact of new mortality rates of COVID-19 on the UK and US stock markets over the period January 1 September 30, 2020. We employed a simple regression model to examine whether new mortality rates contain information beyond the lagged market volatility. By constructing a lockdown dummy variable, we further control for the impact of government lockdown policies on market volatility in our model. Our findings show that new mortality rates caused by COVID-19 pandemic have significant positive impact on volatility of the UK and the US stock markets. We also find that the implementation of lockdown policies provided by the governments reduced the effects of new mortality rates on stock market volatility. In addition, our results are robust to other measurements of volatility. Together our findings suggest that new mortality rates do matter for stock market volatility of these two markets, and lockdown policies mitigate market volatile caused by new mortality rates.
\end{abstract}

Keywords: COVID-19 Pandemic, Stock Market Volatility, Mortality Rates

\section{Introduction}

Since 2020, COVID-19 has continued to spread globally. This unprecedented pandemic will have a profound impact on the structure of politics, the economy, and culture worldwide. Changes in the number of confirmed cases and deaths updated daily by major government websites and scientific research institutes shape investors' sentiments and confidence, thereby affecting the stock market. The Economic Times reported that "U.S. stocks rocketed higher on Monday, with each of the major indexes rallying at least 7\%, after a fall in the daily

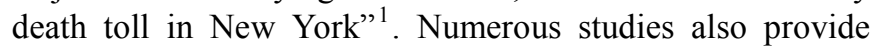
empirical evidence on the impacts of the virus mortality rates

https://economictimes.indiatimes.com/markets/stocks/news/wall-street-soars-7-pe r-cent-on-hopes-of-slowing-coronavirus-deaths/articleshow/75019184.cms on stock market activities, such as stock returns [1] and the stock market index [2]. However, fewer studies have focused on whether the mortality rates of COVID-19 pandemic matter for stock market volatility. This study fills the gap by investigating the effects of daily new mortality rates reported as a result of the COVID-19 pandemic on stock market volatility.

Figure 1 presents the volatility of stock markets and mortality rates in the UK and US during the pandemic. We found that stock markets responded strongly to the outbreak, in both the United States (US) and the United Kingdom (UK). In addition, in response to both countries' decision to impose lockdowns to various degrees after mid-March, the new death rates declined sharply while the volatility of stock markets 
remained low. Therefore, a central question that may be relevant for policymakers and market participants is how to understand the positive relationship between stock market volatility and new death rates during the COVID-19 pandemic, as observed in the two markets.

We examined this issue using data obtained from the FTSE-100 index in the UK and S\&P 500 index in the US. We considered the time period from January 1, 2020 to September 2, 2020. Our empirical results show a positive and significant relationship between death rates and daily stock volatility across UK and US stock markets between 1 January 2020 and 2 September 2020. Our results still hold after controlling for the lockdown period and they are robust to alternative measurements of stock volatility.
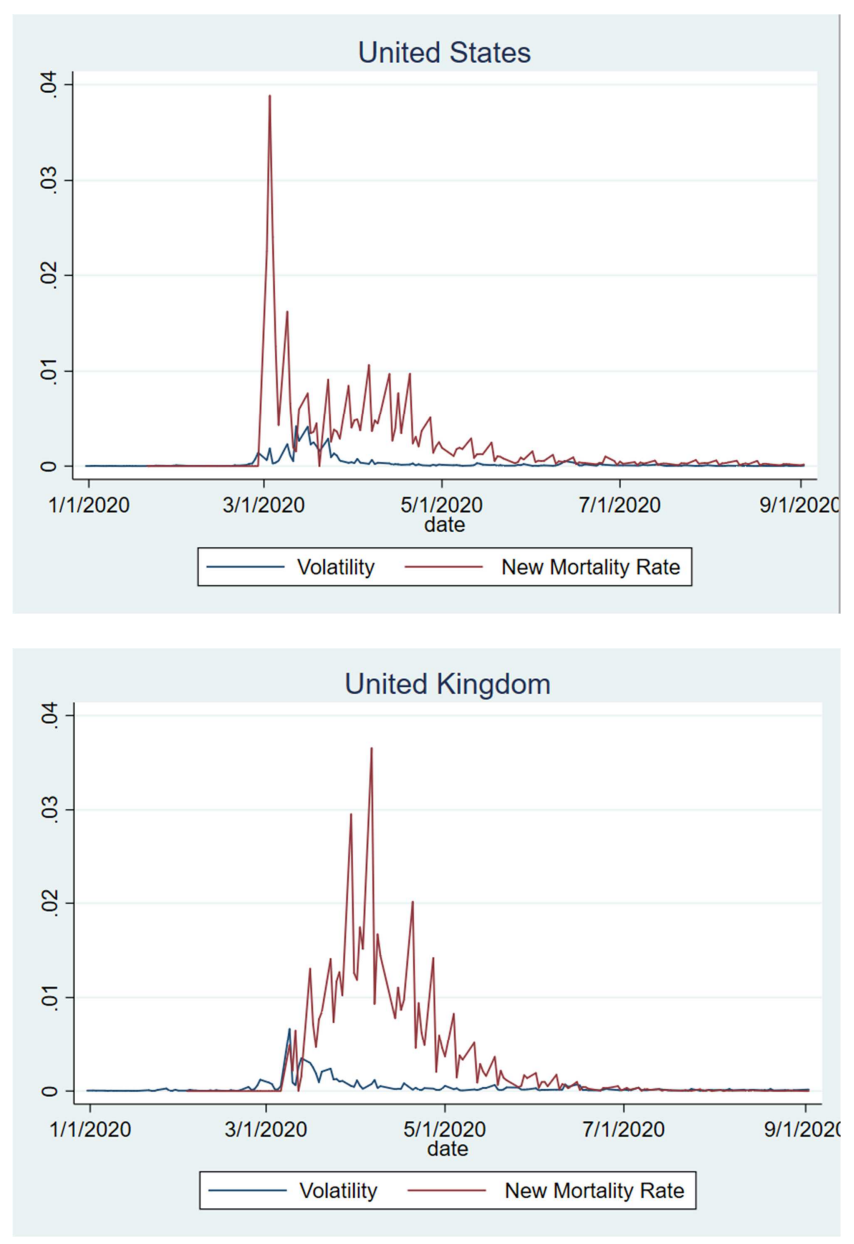

Figure 1. Stock market volatility and new mortality rate.

Our paper contributes to a growing literature on the impact of COVID-19 on the stock market. There is ample empirical evidence showing that the COVID-19 outbreak is a key determinant of the current economic recession [3-5]. Regarding stock market levels, previous studies have investigated the economic impacts of COVID-19 on stock market performance. Al-Awadhi et al [1] demonstrated that this contagious infectious disease had significant negative effects on stock returns. Likewise, Ashraf [6] found that the stock market responded negatively to the pandemic. In addition, several studies have investigated the effects of
COVID-19 on stock market uncertainty. Onali [7] showed that COVID-19 cases had a positive influence on stock market volatility while Baker et al [8] found that the current pandemic has had the largest impact on stock market uncertainty in the history of pandemics. The main findings of our study contribute to this literature by examining the economic impact of COVID-19 on stock market volatility.

The remainder of this paper is organized as follows. Section 2 describes the data and summary statistics. Section 3 presents the main findings of the paper and Section 4 describes the further analysis. Section 5 concludes.

\section{Data and Methodology}

Our sample was composed of two data sets, covering the period from January 1, 2020 to September 2, 2020. We began our sample construction by collecting data on the total number of confirmed COVID-19 cases and deaths in the US and the UK. The data on the virus was collected from the websites of the Centers for Disease Control and Prevention (CDC) and the European Centre for Disease Prevention and Control (ECDC $)^{2}$. Then, we used the ratio of the daily confirmed new deaths to the total cases as a proxy for the new mortality. The data on realized volatility was taken from the Oxford-Man Institute Realized Library version 0.3 [9] ${ }^{3}$. To match these two data sets (daily realized volatility and mortality rates), we added the number of new deaths during non-trading days to the next trading day in each stock market. Table 1 reports the summary statistics for realized stock market volatility and new mortality rates.

We examined the impact of the new mortality rate on stock market volatility in the US and the UK. We specified the following models:

$$
V O L_{i, t}=\alpha_{i}+\beta_{1} \text { New Mortality } \text { Rate }_{i, t}+\varepsilon_{i, t}
$$

and

$$
\begin{gathered}
\operatorname{VOL}_{i, t}=\alpha_{i}+\beta_{1} \text { New Mortality } \text { Rate }_{i, t}+ \\
\beta_{2} \text { Marketlag }_{i, t-1}+\varepsilon_{i, t}
\end{gathered}
$$

where $V O L_{i, t}$ represents the realized volatility for stock market $i$ (the US, UK, and overall market) at time $t$, and the New Mortality Rate $_{i, t}$ represents the new mortality rates for stock market $i$ at time $t$. In the second equation, we included one control variable $\left(\right.$ Marketlag $\left._{i, t-1}\right)$, which is the lagged volatility from other stock market (e.g. when we controlled for the lagged volatility of the FTSE100, we checked whether the new mortality rate still affected the volatility of S\&P500). Our results are presented in next section.

2 We obtained our Centers for Disease Control and Prevention dataset from https://www.cdc.gov/coronavirus/2019-ncov/cases-updates/cases-in-us.html and European Centre for Disease Prevention and Control dataset from https://www.ecdc.europa.eu/en/publications-data/download-todays-data-geograph ic-distribution-covid-19-cases-worldwide.

3 https://realized.oxford-man.ox.ac.uk/. 
Table 1. Summary Statistics.

\begin{tabular}{|c|c|c|c|c|c|c|c|}
\hline & $\mathbf{N}$ & Mean & SD & Min & Max & Skewness & Kurtosis \\
\hline Volatility (US) & 153 & 0.0003 & 0.0007 & 0.0000 & 0.0042 & 3.5535 & 16.5221 \\
\hline Volatility (UK) & 144 & 0.0004 & 0.0008 & 0.0000 & 0.0067 & 4.7758 & 32.8005 \\
\hline Volatility (Overall) & 297 & 0.0004 & 0.0007 & 0.0000 & 0.0067 & 4.2825 & 26.9771 \\
\hline New Mortality Rates (US) & 153 & 0.0021 & 0.0047 & 0.0000 & 0.0388 & 4.7187 & 31.0209 \\
\hline New Mortality Rates (UK) & 144 & 0.0031 & 0.0057 & 0.0000 & 0.0366 & 2.8304 & 13.1285 \\
\hline New Mortality Rates (Overall) & 297 & 0.0026 & 0.0052 & 0.0000 & 0.0388 & 3.5871 & 19.4343 \\
\hline
\end{tabular}

Note: This table describes summary statistics for stock market volatility and new mortality rates in the US market, the UK market and the overall market.

\section{Main Results}

Table 2 reports our main results. We first investigated the impact of new mortality rates on the volatility of the US stock market during the COVID-19 outbreak. The results in column (1) indicate that the new mortality rates had a positive and significant influence on volatility of the S\&P 500 index. The results in column (2) show that the impact from mortality rates hold, even after controlling for the lagged volatility of the FTSE100 index. We found similar results when we examined the UK stock market and the overall market, which includes all observations from the two markets. These results are shown in column (3) through column (6). Moreover, we found that the impact of the new mortality on the volatility of the US stock market was greater than in the UK stock market. Our study adds to the growing literature on the effects of death rates on the stock market during the COVID-19 pandemic. Our findings are consistent with the findings of Al-Awadhi et al [1], showing that information disclosure about the total deaths attributed to COVID-19 have significant negative effects on stock performance. Our results also support previous studies on the response of volatility to information disclosure about COVID-19 [10, 11].

Table 2. Main Results.

\begin{tabular}{|c|c|c|c|c|c|c|}
\hline & \multicolumn{2}{|c|}{ United States } & \multicolumn{2}{|c|}{ United Kingdom } & \multicolumn{2}{|c|}{ Overall Market } \\
\hline & (1) & (2) & (3) & (4) & (5) & (6) \\
\hline & VOL & VOL & VOL & VOL & VOL & VOL \\
\hline New Mortality Rate & $\begin{array}{l}0.0560 * * * \\
(3.67)\end{array}$ & $\begin{array}{l}0.0360 * * * \\
(3.06)\end{array}$ & $\begin{array}{l}0.0360 * * * \\
(3.06)\end{array}$ & $\begin{array}{l}0.0091 * \\
(1.74)\end{array}$ & $\begin{array}{l}0.0447 * * * \\
(4.68)\end{array}$ & $\begin{array}{l}0.0237 * * * \\
(2.92)\end{array}$ \\
\hline Lag Market & & & & $\begin{array}{l}0.8761 \text { *** } \\
(5.31)\end{array}$ & & $\begin{array}{l}0.6194 * * * \\
(3.51)\end{array}$ \\
\hline Constant & $\begin{array}{l}0.0002 * * * \\
(4.72)\end{array}$ & $\begin{array}{l}0.0003 * * * \\
(5.40)\end{array}$ & $\begin{array}{l}0.0003 * * * \\
(5.40)\end{array}$ & $\begin{array}{l}0.0001^{* * *} \\
(4.51)\end{array}$ & $\begin{array}{l}0.0003 * * * \\
(7.17)\end{array}$ & $\begin{array}{l}0.0001^{* *} \\
(2.21)\end{array}$ \\
\hline $\mathrm{N}$ & 153 & 144 & 144 & 144 & 297 & 297 \\
\hline adj. R-sq & 0.140 & 0.064 & 0.064 & 0.655 & 0.099 & 0.459 \\
\hline
\end{tabular}

Note: This table presents the baseline regression on the association between New Mortality rates and the stock market volatility. The dependent variable VOL is the stock market volatility. New Mortality Rate is defined as the ratio of the daily confirmed new deaths to the total cases. Lag Market is the lagged volatility from other stock markets. The t-statistics are reported in parentheses. $* * *, * *$, and * indicate statistical significance at $1 \%, 5 \%$, and $10 \%$ levels, respectively.

\section{Further Analysis}

\subsection{Control for Lockdown}

In response to the COVID-19 pandemic, most governments implemented a series of policies, including lockdowns, travel bans, and stimulus packages, aimed at minimizing the repercussions of the pandemic. An increasing number of studies examine how government responses to COVID-19 affected all aspects of the economy. Zolkipli [12] Bonaccorsi et al [13] and Rahman et al [14] provided empirical evidence on the economic consequences of lockdowns. Narayan et al [15] found that lockdowns have a positive effect on stock returns when the markets are faced with a pandemic. In this paper, we further control for the impact of government policies that mitigate the effects of the pandemic on stock return volatility by constructing a dummy variable. This dummy variable represents the lockdown period in the US market (14.03. 2020 - 18. 04. 2020) and the UK market (16. 03. 2020 -01. 06. 2020). The model presented below:

$$
V O L_{i, t}=\alpha_{i}+\beta_{1} \text { New Mortality Rate } \text { M }_{i, t}+\beta_{2} \text { Marketlag }_{i, t-1}+\beta_{3} D_{\text {Lockdown }}+\varepsilon_{i, t}
$$

where $D_{\text {Lockdown }}$ is the lockdown dummy variable for the corresponding period. Table 3 presents the impact of the new mortality rates on volatility for the US, UK, and the overall market when controlling for the government-implemented lockdown policy. Our results show that the new mortality rates still had a positive and significant impact on the US, UK, and the overall stock market. Moreover, the lockdown policy conducted by these two countries reduced the effect of new mortality rates on volatility as the estimated coefficients of the new mortality rate is smaller than the estimated coefficients in main results (Table 2). These findings are consistent with those of Narayan et al [15] and Baker et al [8]. 
Table 3. Controlling for the Effect of the Lockdown Period.

\begin{tabular}{llll}
\hline & Overall Market & United States & United Kingdom \\
\cline { 2 - 4 } & VOL & VOL & VOL \\
\hline New Mortality Rate & $0.0229^{* * *}$ & $0.0356^{* * *}$ & $0.0229^{* * *}$ \\
& $(2.99)$ & $(2.80)$ & $(2.99)$ \\
Lag Market & $0.6172^{* * *}$ & $0.3469^{*}$ & $0.6172^{* * *}$ \\
& $(3.35)$ & $(1.72)$ & $(3.35)$ \\
Lockdown & 0.0000 & 0.0003 & 0.0000 \\
& $(0.20)$ & $(1.31)$ & $(0.20)$ \\
Constant & $0.0001^{* *}$ & 0.0001 & $0.0001^{* *}$ \\
& $(2.51)$ & $(1.56)$ & $(2.51)$ \\
N & 297 & 153 & 144 \\
adj. R-sq & 0.457 & 0.355 & 0.457 \\
\hline
\end{tabular}

Note: This table presents results after considering the impact of the lockdown period. The dependent variable VOL is the stock market volatility. New Mortality Rate is defined as the ratio of the daily confirmed new deaths to the total cases. Lag Market is the lagged volatility from other stock markets. Lockdown represents the lockdown dummy variable for the corresponding period, which is (14.03. 2020 - 18. 04. 2020) in the US market and (16. 03. 2020 - 01. 06. 2020) in the UK market, respectively. The t-statistics are reported in parentheses. ***, **, and * indicate statistical significance at $1 \%, 5 \%$, and $10 \%$ levels, respectively.

\subsection{Robustness Check}

In this section, we further verified whether our results held when considering another measure of stock market volatility. Following Onali [7], we generated an alternative measure of stock volatility (where the log returns for VIX prices served as proxy). Table 4 shows that the new mortality rates still had a positive and significant impact on VIX, which confirms the robustness of our results.

Table 4. Alternative Measurement.

\begin{tabular}{lllll}
\hline & Overall Market & & United States & United Kingdom \\
\cline { 2 - 5 } & $\mathbf{( 1 )}$ & $\mathbf{( 2 )}$ & $\mathbf{( 3 )}$ & $\mathbf{( 4 )}$ \\
\cline { 2 - 5 } & VIX & VIX & VIX & VIX \\
\hline New Mortality Rate & $35.9329^{* * * *}$ & $25.3752^{* * *}$ & $22.6433^{*}$ & $30.2274^{* * *}$ \\
& $(5.15)$ & $(4.43)$ & $(1.96)$ & $(5.48)$ \\
Lag Market & & $312.4831^{* * *}$ & $283.9902^{* * *}$ & $333.7969^{* * *}$ \\
& & $(5.44)$ & $(3.06)$ & $(8.67)$ \\
Constant & $3.2085^{* * *}$ & $3.1185^{* * *}$ & $3.2243^{* * *}$ & $3.0012^{* * *}$ \\
& $(122.78)$ & $(127.61)$ & $(87.90)$ & $(104.16)$ \\
N & 296 & 296 & 153 & 143 \\
adj. R-sq & 0.194 & 0.468 & 0.396 & 0.599 \\
\hline
\end{tabular}

Note: This table presents the results after using an alternative measure of stock market volatility. The dependent variable VIX is the stock market volatility, which was measured using the log returns for VIX prices. New Mortality Rate is defined as the ratio of the daily confirmed new deaths to the total cases. Lag Market is the lagged volatility from other stock markets. The t-statistics are reported in parentheses. ${ }^{* * *}, * *$, and $*$ indicate statistical significance at $1 \%, 5 \%$, and $10 \%$ levels, respectively.

\section{Conclusion}

In this study, we investigated the impact of new mortality rates on the volatility of the US and UK stock markets. We firstly found that new mortality rates had a positive and significant impact on both stock markets. Besides, our results remained unchanged when considering the effect of the lockdown period for the two markets. We further showed that the implementation of lockdown policies reduced the response of the stock market to the new mortality rates caused by the outbreak. Finally, our results are robust to other measurements of volatility. Overall, our empirical results imply that stock markets respond to released information of COVID-19 during the pandemic period rapidly.

\section{Acknowledgements}

The authors acknowledge funding support from the fundamental research funds for central universities, HEU (3072021CFW0908).

\section{References}

[1] Al-Awadhi, A. M., Al-Saifi, K., Al-Awadhi, A., Alhamadi, S., 2020. Death and contagious infectious diseases: Impact of the COVID-19 virus on stock market returns. Journal of Behavioral and Experimental Finance, 100326.

[2] Yilmazkuday, H., 2020. COVID-19 effects on the s\&p 500 index. Available at SSRN 3555433. 
[3] Fernandes, N., 2020. Economic effects of coronavirus outbreak (COVID-19) on the world economy. Available at SSRN 3557504 .

[4] Barua, S., 2020. Understanding Coronanomics: The economic implications of the coronavirus (COVID-19) pandemic. SSRN Electronic Journal https://doi org/10/ggq92n.

[5] Maital, S., Barzani, E., 2020. The Global Economic Impact of COVID-19: A Summary of Research. Samuel Neaman Institute for National Policy Research.

[6] Ashraf, B. N., 2020. Stock markets' reaction to COVID-19: cases or fatalities? Research in International Business and Finance, 101249.

[7] Onali, E., 2020. COVID-19 and stock market volatility. Available at SSRN 3571453.

[8] Baker, S. R., Bloom, N., Davis, S. J., Kost, K., Sammon, M., Viratyosin, T., 2020. The unprecedented stock market reaction to COVID-19. The Review of Asset Pricing Studies.

[9] Heber, G., Lunde, A., Shephard, N., Sheppard, K., 2009. OMI's realized library, version 0.3. Oxford-Man Institute, University of Oxford.

[10] Baek, S., Mohanty, S. K., \& Mina, G., 2020. COVID-19 and Stock Market Volatility: An Industry Level Analysis. Finance Research Letters, 101748.
[11] Phan, D. H. B., Narayan, P. K., 2020. Country responses and the reaction of the stock market to COVID-19-A preliminary exposition. Emerging Markets Finance and Trade, 56, 2138-2150.

[12] Zolkipli, M. F., 2020. Data-driven dynamic clustering framework for mitigating the adverse economic impact of COVID-19 lockdown practices. Sustainable Cities and Society, 62,102372 .

[13] Bonaccorsi, G., Pierri, F., Cinelli, M., Flori, A., Galeazzi, A., Porcelli, F., Pammolli, F., 2020. Economic and social consequences of human mobility restrictions under COVID-19. Proceedings of the National Academy of Sciences, 117, 15530-15535.

[14] Rahman, M. A., Zaman, N., Asyhari, A. T., Al-Turjman, F., Bhuiyan, M. Z. A., Zolkipli, M. F., 2020. Data-driven dynamic clustering framework for mitigating the adverse economic impact of Covid-19 lockdown practices. Sustainable Cities and Society, 62, 102372.

[15] Narayan, P. K., Phan, D. H. B., Liu, G., 2020. COVID-19 lockdowns, stimulus packages, travel bans, and stock returns. Finance Research Letters. https://doi.org/10.1016/j.frl.2020.101732. 